\title{
Optical and Electrical Properties of the $\mathrm{Ge}_{10} \operatorname{In}_{\mathrm{x}} \mathrm{Se}_{(90-\mathrm{x})}$ Amorphous Thin Film
}

\author{
N. H. Moussa \\ Physics Department, Faculty of Science, Al-Azhar University (Girls), \\ Nasr City, Cairo, Egypt
}

\begin{abstract}
THIN films of $\mathrm{Ge}_{10} \mathrm{In}_{\mathrm{x}} \mathrm{Se}_{90-\mathrm{x}}(\mathrm{x}=5,10$, and 15\%) were prepared by the conventional thermal evaporation technique. X-ray diffraction measurements have shown that $\mathrm{Ge}_{10} \mathrm{In}_{\mathrm{x}} \mathrm{Se}_{90-\mathrm{x}}(\mathrm{x}=5,10$, and $15 \%)$ thin film form has an amorphous nature. The optical and electrical properties of $\mathrm{Ge}_{10} \mathrm{In}_{\mathrm{x}} \mathrm{Se}_{90-\mathrm{x}}($ where $\mathrm{x}=5,10,15 \%)$ were studied. Transmittance and reflectance measurements were used to calculate the optical energy gap, band tail width of the localized states and the optical constants [refractive index $(\mathrm{n})$, absorption index $(\mathrm{K})$ and absorption coefficient $(\alpha)$, real and imaginary parts of dielectric constant $\left(\varepsilon^{\prime}, \varepsilon^{\prime \prime}\right)$ respectively].

The optical bands were found to decrease with increasing In content, while the width of the tails of the localized state increases. The results of the electrical conductivity measurements showed that the conductivity increased and activation energy of conduction decrease with increasing In content. The obtained results show that the activation energy was less than optical band gap for the investigated samples.
\end{abstract}

\section{Introduction}

Amorphous chalcogenide films have current applications in optical memories, photonic crystals and optics. Efforts are being made to develop chalcogenide based rewritable optical memories [1,2]. The chalcogenid glasses have recently received considerable attention because they provide solid state physicists with new challenging fundamental problem and because of their possible technological applications $[3,4]$.

The optical and electrical properties of GeSe chalcogenide glasses have been extensively studied, Adding Indium to Ge-Se glass not only enlarges their region of glass formation but also, creats composition and configuration disorder $[5,6]$. Various works $[7,8-12]$ are concerned with the optical and electrical properties of Ge-In-Se.

The optical properties of amorphous semiconductors have been the subject of many recent papers [13-18]. It is well known that the optical gap of amorphous semiconductors alloys strongly depends on their compositions. The study of the optical constants of materials is interesting for many reasons. First, the use of materials in optical fibers and reflected coating requires accurate knowledge of their optical constants over wide ranges wave length. Second, the optical properties of all materials are related to their atomic structure, electronic band structure and electric properties. In the present work we will determine the optical energy gap, the width of localized states, absorption coefficient $(\alpha)$, refractive (n) and extinction coefficient $(\mathrm{K})$, real and imaginary parts of dielectric constants $\left(\varepsilon^{\prime}, \varepsilon\right.$ ') for $\mathrm{Ge}_{10} \mathrm{In}_{\mathrm{x}} \mathrm{Se}_{90-\mathrm{x}}$ (where $\left.\mathrm{x}=5,10,15 \%\right)$ amorphous thin films, that is, by using transmittance and reflectance data spectra.

The Dc conductivity was measured for $\mathrm{Ge}_{10} \mathrm{In}_{\mathrm{x}} \mathrm{Se}_{90}$ (where $\mathrm{x}=5,10$ and $15 \%$ ) amorphous thin films to determine the activation energy of conduction. Davis and Mott gave a model which gives a good explanation for the Dc conductivity of the amorphous semiconductors [19].

\section{Experimental}

The amorphous thin films of the system $\mathrm{Ge}_{10} \mathrm{In}_{\mathrm{x}} \mathrm{Se}_{90-\mathrm{x}}$ (where $\mathrm{x}=5,10$ and $15 \%$ ) were prepared on two steps using two different techniques.First preparing the samples in solid bulk glassy ingots and then preparing the amorphous thin films. 
The chalcogenide glasses of the system were prepared using the well-known melt quenching technique. High purity (99-999\%) Ge, In and Se materials in appropriate atomic percentages were weighted on a monopan balance having an accuracy of $\pm 0.001 \mathrm{gm}$, the powder of each sample was thoroughly mixed to ensure its stoichiometric compostion, then contained in a quartz glass ampoule. The contents of the ampoule were sealed into a vacuum of $10^{-4}$ torr and heated in a furnace to $1000^{\circ} \mathrm{C}$ for $10 \mathrm{hr}$ for all the glasses. During the synthesis, the molten was shacked to ensure a homogenous glassy alloy. The molten samples were rapidly quenched in ice-water mixture to produce a glassy solid. Thin film samples were prepared by thermal evaporation technique from bulk materials, using a high vacuum coating unit type [Edwards 306-A,boat]. The vapor of the materials powder was deposited on clean glass substrates under vacuum of $2 \times 10^{-5}$ torr to avoid reaction between the vapor and atmosphere and to obtain good homogenous films. The substrates were rooted during the evaporation process to ensure the homogeneity. The amorphous nature of thin films were confirmed by X-ray diffraction (XRD) for the investigated samples.

The reflection $(\mathrm{R})$ and the transmission $(\mathrm{T})$ at normal incidence were measured using double beam spectrophotometer model (Jasco corp. V. 570).

The obtained transmittance and reflectance data against incident light wave length were used to calculate the absorption coefficient and the optical constants.

The dc electrical conductivity was measured using home design cryostat tube. The tube was evacuated using rotaring pump $\left(\right.$ vacuum $\simeq 10^{-3}$ torr). The electrical resistance of the sample was measured using a programmable electrometer (Keithey model E617A) with measuring the electrical resistance directly.

\section{$\underline{\text { Results and Discussion }}$}

XRD patters for the investigated composition in thin film forms for $\mathrm{Ge}_{10} \operatorname{In}_{\mathrm{x}} \mathrm{Se}_{90-\mathrm{x}}(\mathrm{x}=5,10$ and $15 \%$ ) with thickness $400 \mathrm{~nm}$ are illustrated in Fig. 1. The obtained pattern indicated that the thin forms of $\mathrm{Ge}_{10} \mathrm{In}_{\mathrm{x}} \mathrm{Se}_{90-\mathrm{x}}(\mathrm{x}=5,10$ and $15 \%)$ have an amorphous structure.

\section{The optical measurements}

The reflection $(\mathrm{R})$ and transmission $(\mathrm{T})$ spectra for thin films were obtained as a function of the wave length energy as shown in Fig. 2 (a \& b).

The influence of Indium concentration in $\mathrm{Ge}_{10} \operatorname{In}_{\mathrm{x}} \mathrm{Se}_{90-\mathrm{x}}(\mathrm{x}=5,10$, and $15 \%)$ thin films on the optical properties of the prepared films was studied extensively. Figures 2 a \& b illustrated the variation of wave reflection and wave transmition with the wave length $(\lambda)$ in the range $(400-900 \mathrm{~nm})$ and from these figures it is clear that reflection increased with increasing indium concentration while the transmutation decreased.

The absorption coefficient $(\alpha)$ was calculated using $\mathrm{R}$ and $\mathrm{T}$ [20]

$$
\alpha=\frac{1}{t}[\ln (1-R \rrbracket / T]
$$

where $(t)$ is the film thickness

The optical gap defined as the Tauc gap [21] was obtained by extrapolating the high absorption optical data according to the empirical formula:

$$
\alpha \hbar \omega=\beta\left(\hbar \omega-E_{\text {opt }}\right)^{n}
$$

where $(\omega)$ is the angular frequency of the radiation, $(\beta)$ is constant called band parameter, $\mathrm{E}_{\mathrm{opt}}$ is the optical energy gap and exponent (n) is the power which characterizes the transitions process may take values $(1 / 2,3 / 2,2,3)$ transition process, (n $=1 / 2)$ for a direct allowed transition, $(n=3 / 2)$ for a direct forbidden transition, $(\mathrm{n}=2)$ for on indirect allowed transition and $\mathrm{n}=3$ for an indirect forbidden transition. Plots of $,(\alpha \hbar \omega)^{1 / 2}, \alpha \hbar \omega$ $(\alpha \hbar \omega)^{1 / 3},(\alpha \hbar \omega)^{3 / 2}$ and $(\alpha \hbar \omega)^{2 / 3}$ against the photon energy.

The data reveals that in the present case $n=2$, indicating an indirect transition for the most amorphous compounds [20].

From the plots of $(\alpha \mathrm{h} v)^{1 / 2}$ as a function of photon energy, $\mathrm{E}_{\mathrm{opt}}$ values can be obtained by extrapolation of the linear region of the plots to the photon energy axis for indirect transitions as shown in Fig. 3. The tail-width for the absorption spectra can also be used to analyze possible changes in the glass structure.

For many amorphous materials an exponential dependence of absorption coefficient on photon 



Fig. 1. X- ray diffraction pattern for thin film systems 




Fig. 2a. The reflection spectra $(R)$ versus wavelength $(\lambda)$ for glass systems



Fig. 2b. The Transmittion spectra (T) versus wavelength $(\lambda)$ for glass systems



Fig. 3. Tauc plats. The relation $(\alpha \hbar \omega) 1 / 2$ versus photon energy for glass systems 
energy (hu) is hold over a wide range and given by Urbach [22].

$$
\alpha(v)=B \exp \left[h v / E_{u}\right]
$$

where (B) is a constant, (hu) is the photon energy and $\left(E_{u}\right)$ is the Urbach energy which indicates the width of the band tail of the localized states in the band gap.

The Urbach energy $\left(E_{u}\right)$ values of the present samples were determined by taking the reciprocals of the slopes of the linear portion of the $\ln (\alpha)$ versus (hu) plots. The obtained values of $\mathrm{E}_{\mathrm{opt}}$ and $\mathrm{E}_{\mathrm{u}}$ are listed in Table 1. The formation of defects like anomalous bonds with fluctuation in bond angle distortions is the reasons for the observed increase in Urbach energy [23].

The optical constants, refractive index (n) and extinction coefficient $(\mathrm{K})$, were determined using the following equations [24].

$$
\begin{aligned}
& \mathbf{n}=\left[\frac{1+\sqrt{\mathbf{R}}}{1-\sqrt{\mathbf{R}}}\right] \\
& \mathrm{K}=\frac{2 \mathrm{x}}{4 \pi}
\end{aligned}
$$

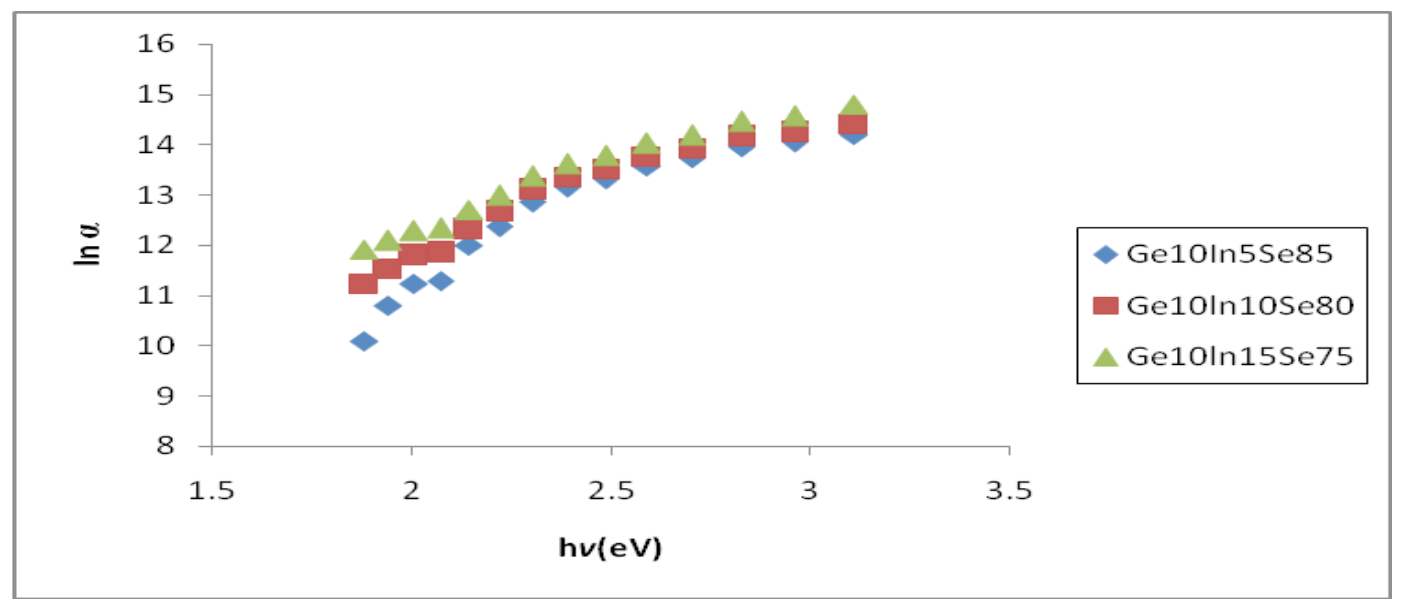

Fig. 4.

The plots of the refractive index (n) as a function of wave length $(\lambda)$ are shown in Fig. 5. The large In-atoms may cause more polarization and the increase of refractive index in relation with polarization [25]. The extinction coefficient $(\mathrm{K})$ as a function of wave length $(\lambda)$ indicates that the extinction coefficient decreased with increasing wave length and increased with increasing Indium content (Fig. 6).

The real and imaginary parts of the dielectric constants $\left(\varepsilon^{\prime}, \varepsilon "\right)$ were determined using the relation of Sharma et al. [26]. Both the real part and the imaginary part of the dielectric constant are measured for the prepared films using the relations:

$$
\varepsilon^{\prime}=\mathrm{n}^{2}-\mathrm{k}^{2} \quad, \quad \varepsilon^{\prime \prime}=\mathrm{n}^{2}-\mathrm{k}^{2}
$$

The values of $\left(\varepsilon^{\prime}\right)$ and ( $\left.\varepsilon^{\prime \prime}\right)$ depend on refractive index (n) and extinction coefficient $(\mathrm{k})$.
Figures 7 and 8 illustrated the variation of $\left(\varepsilon^{\prime}\right)$ and $\left(\varepsilon^{\prime}\right)$ as a function of wavelength. It is observed that their values increase with increasing Indium concentration and are attributed to an increase in the density of the charged defect states [27] and increased disorder in the structure.

\section{Dc electrical conductivity}

The electrical conductivity $(\sigma)$ with the reciprocal temperature for $\mathrm{Ge}_{10} \operatorname{In}_{\mathrm{x}} \mathrm{Se}_{90-\mathrm{x}}(\mathrm{x}=5,10$ and $15 \%$ ) thin films are shown in Fig. 9. The Dcconductivity as a function of temperature follows the Arhinian type of the conductivity relation in the form of Matt and Davis [20]:

$$
\sigma=\sigma_{0} \exp \left(-\Delta \mathrm{E} / \mathrm{K}_{\beta} \mathrm{T}\right)
$$

where $\left(\sigma_{0}\right)$ is the conductivity pre-exponential factor, included charge mobility and density of states, $h$ is the plank's constant, $K_{\beta}$ is the Boltzmann constant, $\Delta \mathrm{E}$ is the dc-conduction 


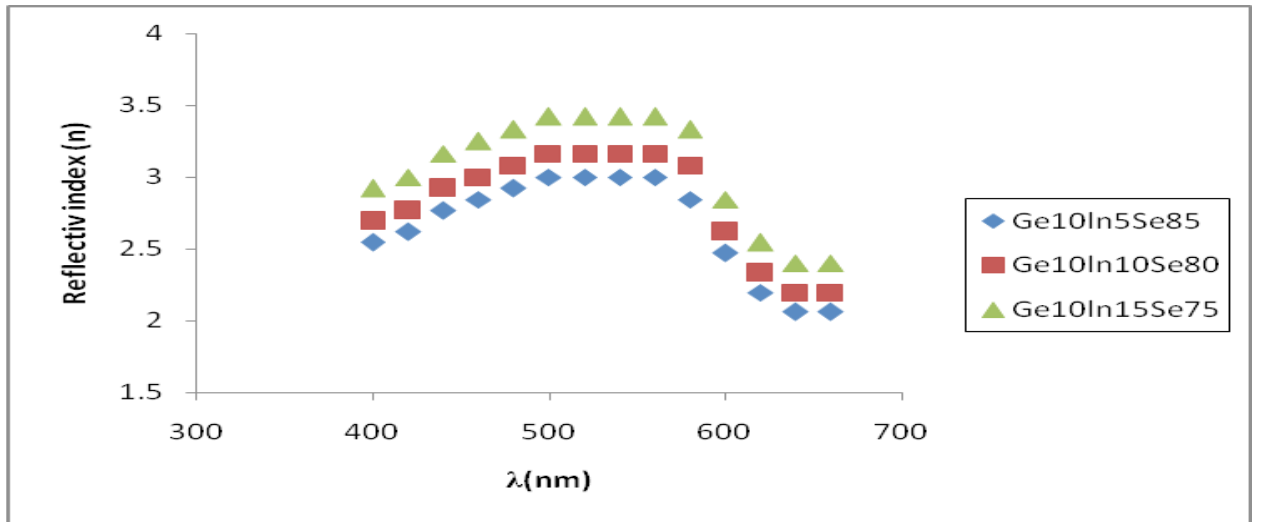

Fig. 5. Dependence of refractive index (n) on the wavelength $(\lambda)$ for glass systems.

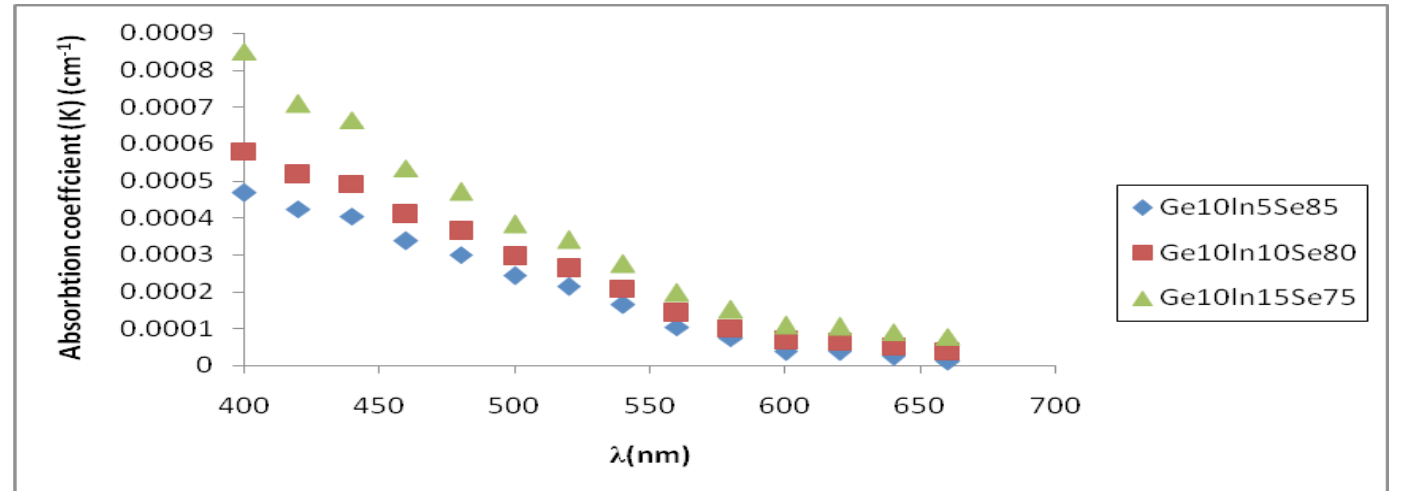

Fig. 6. Dependence of extinction coefficient $(K)$ on the wavelength $(\lambda)$ for glass systems.

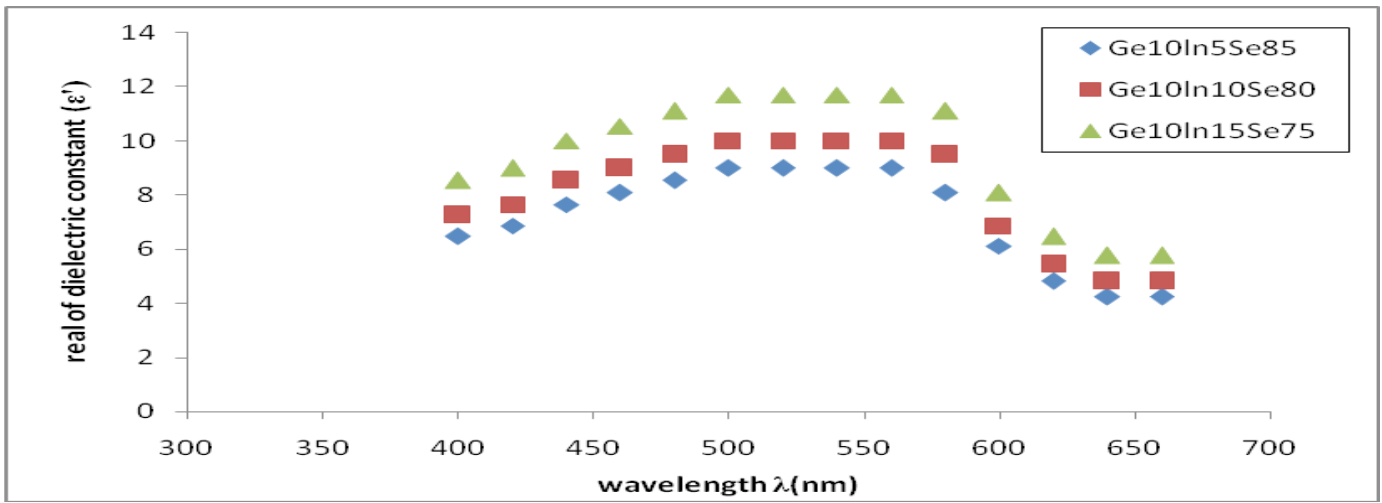

Fig. 7.

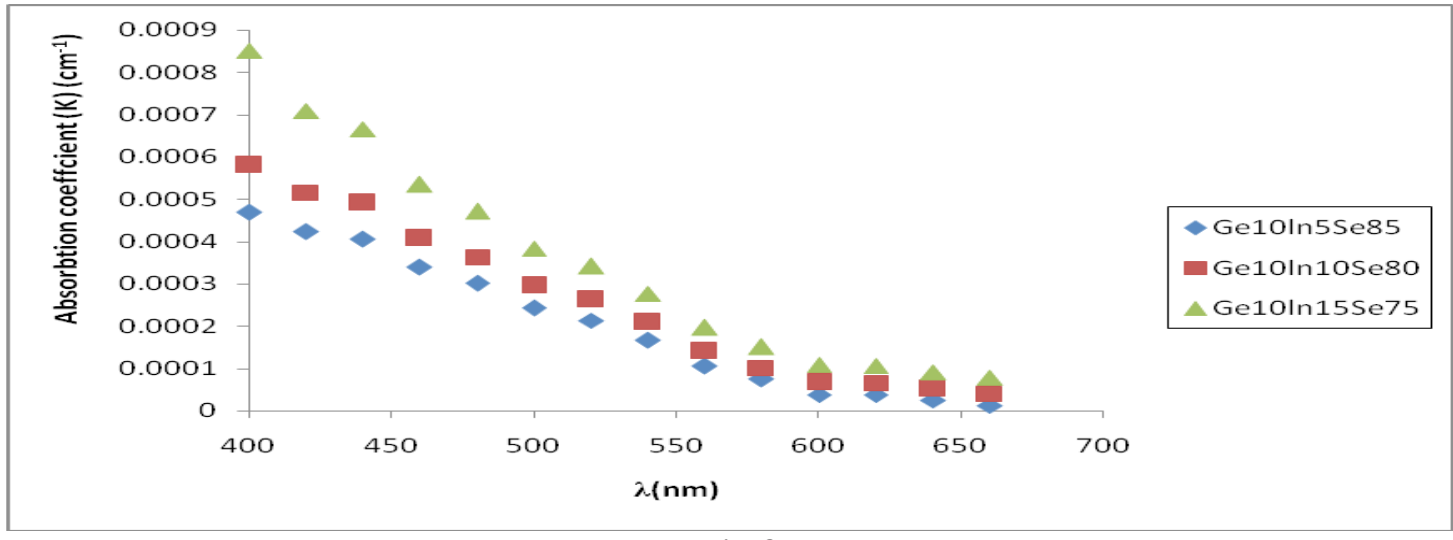

Fig. 8.

Egypt. J. Phys. Vol. 45 (2017) 
activation energy. $\Delta \mathrm{E}$ were calculated from Fig. 9 and listed in Table 1 . The activation energy $\Delta \mathrm{E}$ decreases with increasing indium content. The observed decrease in $\Delta \mathrm{E}$ with the addition indium content is similar to that observed for the optical energy gap. It was found that the values of the activation energy of conduction (E) are less than half the optical energy gap $\left(\mathrm{E}_{\text {opt }}\right)$. of the investigated samples. [28,29]. Therefore, an impurity band must exist within the mobility gap, which determines the activation energy and gives an indication that the Fermi level is presumably displaced from the center of the mobility gap towards the valence band.
The conductivity $(\sigma)$ increases with increasing. In content this confirmed that the change in $(\sigma)$ is connected to corresponding change in $(\Delta \mathrm{E})$.

The conductivity $(\sigma)$ is the sum of two components:

$$
\sigma=\sigma_{\text {hop }}+\sigma_{\text {ext }}
$$

where $\sigma_{\text {hop }}$ is the contribution of conduction due to hopping between the nearest localized states and $\sigma_{\text {ext }}$ is contribution of conduction between the extended states. The contribution occurs via variable range hopping of the charge carries in the localized states near the Fermi level [30]

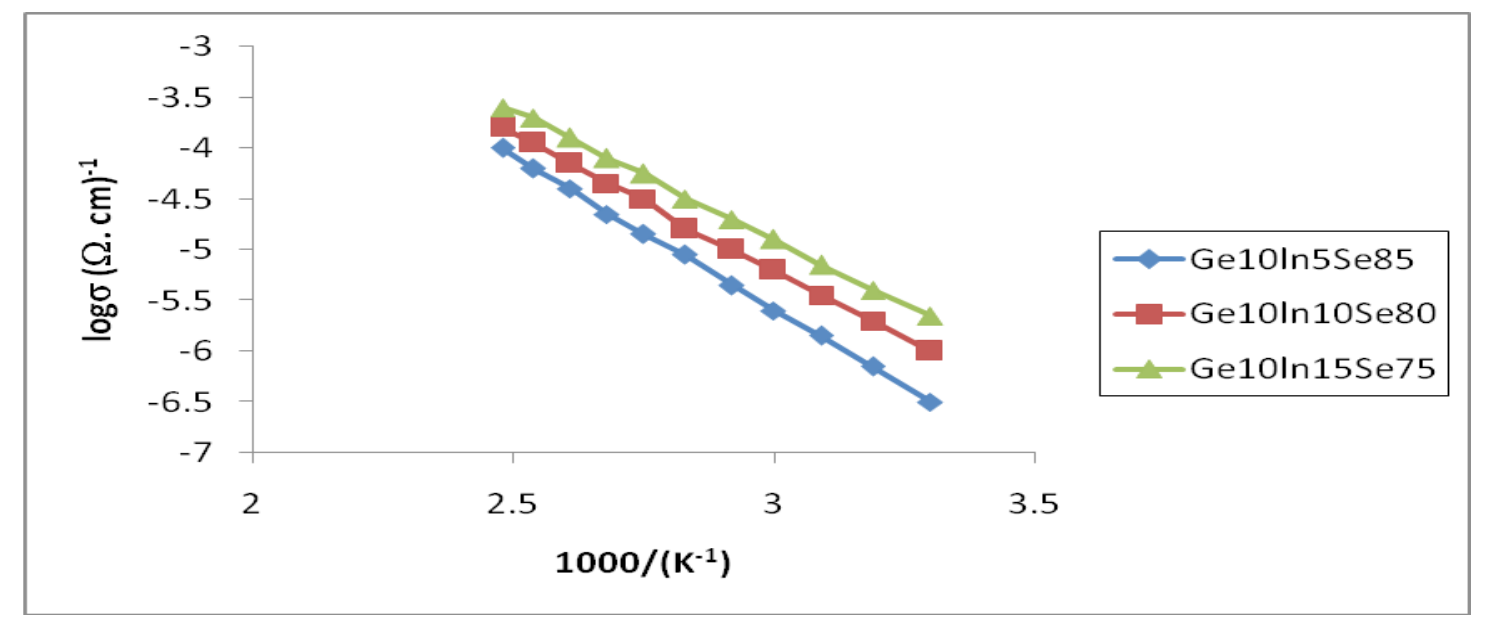

Fig. 9. Temperature dependence of De electric conductivity for $\operatorname{Ge}_{10} \operatorname{In}_{\mathrm{x}} \mathrm{Se}_{90-\mathrm{x}}(\mathrm{x}=5,10$ and $15 \%)$ films.

TABLE 1. The values of the optical energy gaps $\left[E_{\text {opt }}\right]$, urbach energy $\left(E_{u}\right)$ and activation energy of conduction $(\Delta E)$ for $\mathrm{Ge}_{10} \operatorname{In}_{\mathrm{x}} \mathrm{Se}_{90-\mathrm{x}}(\mathrm{x}=5,10$ and $15 \%)$.

\begin{tabular}{|lccc|}
\hline Composition & $\mathbf{E}_{\text {opt }}(\mathbf{e V})$ & $\mathbf{E}_{\mathbf{u}}(\mathbf{e V})$ & $\Delta \mathbf{E}(\mathbf{e V})$ \\
\hline $\mathrm{Ge}_{10} \mathrm{In}_{5} \mathrm{Se}_{25}$ & 1.80 & 0.42 & 0.60 \\
$\mathrm{Ge}_{10} \mathrm{In}_{10} \mathrm{Se}_{80}$ & 1.75 & 0.55 & 0.53 \\
$\mathrm{Ge}_{10} \mathrm{In}_{15} \mathrm{Se}_{75}$ & 1.6 & 0.60 & 0.50 \\
\hline
\end{tabular}

\section{Conclusion}

$\mathrm{Ge}_{10} \operatorname{In}_{\mathrm{x}} \mathrm{Se}_{90-\mathrm{x}}(\mathrm{x}=5,10$ and $15 \%)$ films were obtained by thermal evaporation technique on glass and the amorphous nature of systems were ensured from XRD measurements. The optical absorption measurements indicate that the absorption mechanism is due to the indirect transition. The optical energy gap $\left(\mathrm{E}_{\mathrm{opt}}\right)$ decreased while the width of band tail $\left(\mathrm{E}_{\mathrm{u}}\right)$ increase with increasing In content. On the other hand the values of (n, $\varepsilon, \varepsilon ")$ and extinction coefficient $(\mathrm{k})$ increase with increasing In content. The electrical results of $\mathrm{Ge}_{10} \operatorname{In}_{\mathrm{x}} \mathrm{Se}_{90-\mathrm{x}}(\mathrm{x}=5,10$ and $15 \%)$ thin films indicate that the electrical conductivity $(\sigma)$ increased and the activation energy for conduction $(\Delta \mathrm{E})$ decreased with increasing the In content. Therefore, an impurity band must exist within the mobility gap, which determines the activation energy and gives an indication that the fermi level is presumably displaced from the center of the mobility gap towards the valence band. 


\section{References}

1. Ghoneim, D. et al., Chalcogenide Letters, 7-5 307 (2010).

2. Bindra, K.S. et al., Chalcogenide Letters, 3-9 (2006) 133.

3.Hernandez, J.G., Gruz, E.L., Limon, M.V., Dsdtrand, Chao, B.B., Ovshinsky,S.R., Solid State Commun. 95, 593 (1995)

4. Seddon, A.B., J. Non-Cryst. Solids, 184,44 (1995)

5. Abdel-Rahim, M.A., Hafiz, M. M., Shamekh, A.M., Physica. B: Condensed Matter, 369 143154 (2005).

6. Abd El-Naeim,A.M., Aly, K.A., Afify, N. and Abousehlly, A.M., Jorunal of Alloys and Compounds, 491(2010) 85-91.

7. Shaaban, E.R., Yahia, I.S. and Fadel, M., Journal of Alloys and Compounds , 469 427432 (2009)

8. H.E. Atyia, Physica B: Condensed Matter, 403 16-24 (2008)

9. Abd El-Ghani, H.A., Abd ElRahim,M.M. Wakkad,M.M. , Abosehli, A. and Assraan,N. Physica B: Condensed Matter. 381156-163 (2006).

10. Khan, Z.H., Zulfeqaur,M.,Kumar,A. and Husain, M., Canadian Journal of Physics, 80 9-27 (2002)

11. Shira, V.S., C.V., Boussard,C., Pledel, P. and Lucac, J., Mater. Sci. Eng., B 127138 (2006)

12. Popescu, M., Non Crystalline Chalcogenide, Kluwer Academic, Boston (2001).

13. Gangwar, A.P., Sexena, A.K. and Tiwari,S.K., Int. J. Advanced Engineering Research and Sci., 4129 (2017)

14. Amer, H.H., Mongy, A., Mongy, A. and Wahab, A.A., Arab J. of Nuclear Science and Applications, 50, 136 (2017)

15.Swarup. S. , Nigam, A.N. and Kumar, A., J. Phs. B 162,177 (1990)
16. Iman, M.M.A., Bhandari,D. and Sakena,N.S. , J. Mater. Sci. Eng. A 29256 (2000)

17. El-Sayed M. Farag. J. Mater, Sci. 15, 19 (2004)

18. Abou El-Hassan, S. and Hammed, M., Phys. Sat. Sal. A. 185413 (2008)

19. Davis, E.A. and Mott,N.F., Phill. Mag. 22, 903 (1970)

20. Mott, N.F. and Davis, E.A. "Electronic processes in non crystalline materials" Oxford University Press, Oxford, (1971).

21. Tauc, J. , Amrphous and Liquid Semiconductors, Plenum. New York 159 (1974)

22. Urbach F., Ph. Rev. 921324 (1953)

23. Adel, G.H. ,Al-Azhar Pull. Sci., 23 (2012) P.1.

24. Bahagat, A.A., Abd Rabo, A.S., Iman A. Mahdy and Mahmoud, E.A., Optics and Laser Technology 40 ,1061 (2008)

25. Mainika, S.P.,Katyal, S.C. and Thakur, N., A study of impurities (Ag, Bi \& Ge) on the optical properties of Se-Te thin films. Journal of Nonoxide Glasses 1, 90-95 (2009)

26. Sharma, P., Sharma,V. and Katyal,S.C., Variaiton of optical constants in $\mathrm{Ge}_{10} \mathrm{Se}_{60} \mathrm{Te}_{30}$ thin film, Chalcogenide Letters, 3,73-79 (2006)

27. Sharma, P. and Katyal, S.C., Materials Chemistry and Physics, 112, 892 (2008)

28. Pandey,V. , Tripathi, S.K. and Kumar, A Physica B: Condensed Matter, 388, 200-205 (2007)

29. Kovaluk, Z. D., Katerynchuk,V., Savchuk,A.K. and Sydor, O.M., Material Science and Engineering B: Solid State Material for Advanced Technology, 109, 252255 (2004).

30. Mott, N.F., Philas. Mag. 32, 961, (1975)

(Received: 2 / 1/2017; accepted: 18 /7 / 2017 ) 
دراسة الخواص الضوئية و الكهربية للزجاج الثالكوجنيت نعيمة حسين موسى الفيزية ـكلية العلوم (فرع البنات ) جامعة الازهر - مدينة نصر - القاهرة

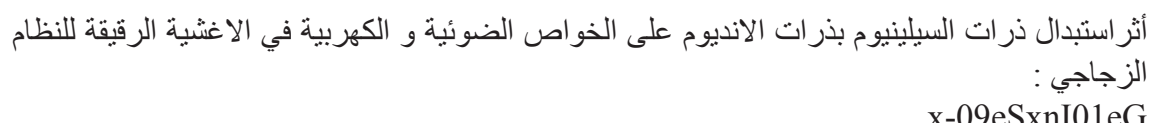

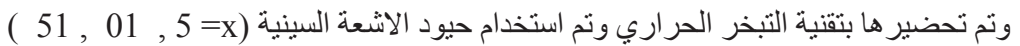

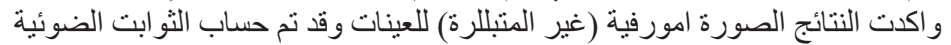

(Refractive index, extinction coefficient, real and imaginary dielectric constant and absorption coefficient )

ووجد أن فجوة الطاقة تقل بزيادة الإنديوم ووجد أن طاقة التنشيط للعينات تقل باستبدال اللينيوم بالإنديوم 